a the case, I diaguosed a large multilocular ovarian tumour attiached to the right ovary.

I operated in March, Dr. Jameson of Dublin, Dr. Greenwowd, and others being present. On opening the abdomen and exposing the tumour, I found very strong and general adhesions, particularly on the right side, which were divided by the actual cautery. Several bleeding points were also cauterized. About four gallons of fluid were drawn off, and the tamour extracted. The pedicle was divided by my own adhesion clamp. The left ovary being also diseased, I divided it with a knife, and seared the cut edges with the cautery iron. Before closing the wound, I sponged the pedicle to see if there was any hæmorrhage. This slight interference was sufficient to disturb the burnt surface; and, therefore, it was thought judicious to transfix the pedicle by a double ligature, and leave the ends outside, in the manner recommended by Dr. Clay, of Maxchester. The edges of the incision were brought together in the usual manner.

The recovery of this patient was slow but continuous, and ahe was quite well in five weeks.

This case taught me, what after-experience has confirmed, 纾at, having divided the pedicle by cautery, one may be sure (1) that all the vessels are closed, and that it is advisable at onee to allow the pedicle to sink back to its normal position; and (2) that the only chance of secondary hæmorrhage arises From subsequent interference.

$$
\text { (To be concluded.) }
$$

\section{A SUGGESTION IN AID OF LARYNGOSCOPY.}

By GEORGE JOHNSON, M.D., F.R.C.P., FEYSICLAN TO KING'S COLLEGE HOSPITAL, PROFBSSOR OF MEDICIME IN KING'S COLLEGE.

ON a former occasion I made some suggestions for facilitating 3he asse of the laryngoscope, which have been very generally aropted, and which I have reason to believe have been found of mich use.* I have now to describe a very simple contrivance for obviating one of the most serious inconveniences to which laryngoscopists are exposed: I mean the painful glare of light in the eyes of the operator, whether he employs the light of aze or that of a lamp. Everyone who has worked much with the laryngoscope must have experienced the unpleasant effect resulting from continued exposure of the eyes to the glare of light. So long as the operator looks through a perfoseded reflector placed in front of one eye there is no mode of from the annoyance in question. It may be avoided mirely by the simple device of a black shade over the eyes, Whe shade being placed beneath the reflector on the forehead, and fastened by two hooks and eyes to the band which passes sound the head. The shade is made of a piece of card covered

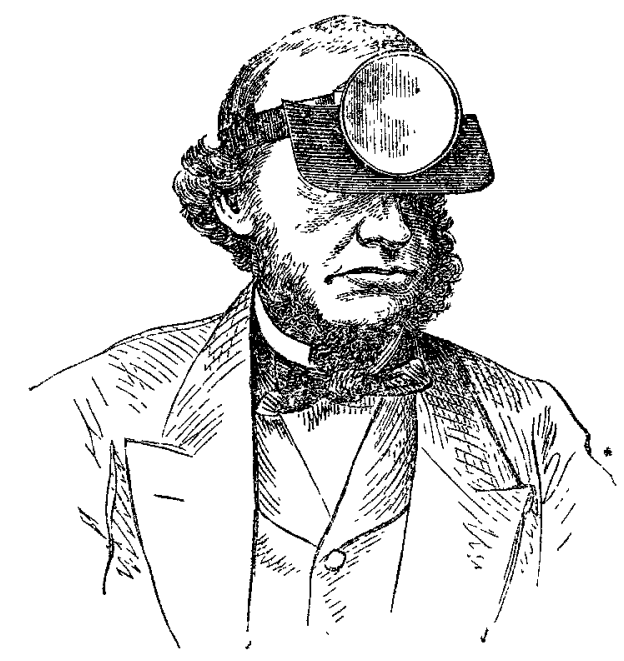

rith black silk. The eyes are sewn on the elastic band which 3alds the reflector, that on the right being fixed on the inner

\footnotetext{
* Some time since, I received from an eminent provincial physician a note, Trom which the following is an extract: "I had bothered over the laryngoscope a long time and done very little with it until I saw your suggestion of putting the reflector on the forehead; now I find it of very great use."
}

side of the buckle, so as not to interfere with the movement of the band through the buckle. The hooks-such as ladies use for holding up their dresses-are attached to the upper edge of the shade, one near each end. The shade therefore can be quickly attached to the band, and as readily removed.

The effect of the shade is to protect the eyes entirely from the direct glare of the sun or of the lamp, while the light reflected from the laryngeal mirror passes beneath the shade to the eyes of the operator, and the result is a more distinct view of the laryngeal image, with much less of fatigue and annoy. ance to the eyes than in the ordinary mode of practising laryngoscopy. When a lamp is used, its flame should be about the level of the top of the patient's head. The shade must be sufficiently wide to protect the eyes from the direct glare of the lamp or of the sun, without obstructing the rays reflected from the laryngeal mirror. The shade can be made and fixed without the help of an instrument-maker, and I commend this simple contrivance to the notice of my fellow-workers in the interesting field of laryngoscopy.

I see that a recent writer in THE LANCET, Dr. Eben. Watson of Glasgow, expresses his opinion that the value of the laryngoscope has been over-estimated by some whom he considers too zealous advocates of this new method. With regard to the alleged frequency of polypous and other morbid growths in the larynx, he appears to be sceptical, and "cannot repress the wish that laryngoscopists had these strange visions granted to them a little less frequently." Dr. Eben. Watson apparently suspects that some of these visions have been of a spectral character. He also expresses his opinion that "laryngoscopy is neither required for nor assists in the ordinary topical medication of the larynx, and that it is a most unsafe guide in surgical operations on that organ." The removal of warts from the vocal cords by the aid of the mirror he speaks of as " rather a wonderful feat in surgery," and he evidently doubts the possibility of such a proceeding. I should have thought that the number of well-authenticated cases in which morbid growths in the larynx have been discovered and removed by the aid of the laryngoscope would suffice to convince even the most sceptical that growths in this situation are not uncommon, and that their removal by the aid of the mirror presents no insuperable difficulty. I have myself within the last two months removed a tumour from one of the vocal cords in no less than three cases. I have the morbid growths to show as evidence that "this rather wonderful feat" has been accomplished, and I shall shortly publish full particulars of the cases. In not one of these cases could the cause of the hoarseness have been ascertained without the aid of the laryngoscope, much less would it have been possible to carry out a successful plan of treatment, resulting, as it has done in each case, in the complete restoration of the voice.

Savile-row, August, 1865.

\section{PATHOLOGICAL CONSERVATIVE SURGERY:} ITS DEFINITTON AND PURPOSE.

BY FREDERICK JAMES GANT, F.R.C.S., SUBGEON AND PATHOLOGICAL ANATOMIST TO THE ROYAL FREB HOSPITAT.

IN my introductory lecture last October, on the "Pathological Practice of Surgery," which was published in TH LANCET, I dwelt on the conservative character of all surgical treatment when guided, regulated, and determined by (foreknowledge of) the natural courses and tendencies of injuries and diseases to or towards recovery. This aspect of their vital history implying the operation and resources of a self-restorative power inborn and inherent in the human body, the practice of surgery thence derived necessarily becomes conservative or preservutive of its anatomical and functional integrity. Moreover, as the subjection and adaptation of such practice to the requirements of the self-restorative organism reduces our treatment to the least amount of assistance necessary, as well as indicating the kind thereof, and the earliest occasion for such assistance; this limitation, in point of degree, also confers a conservative or non-interfering character on the practice of surgery; and, observe, by ever referring the surgeon to clinical observation of the vital history of injury and disease, rules our art from the sure and commanding ground of patho$\operatorname{logy}$.

Pathological Conservative Surgery, as this contribution of 